Dr.J. P. Bushe-Fox before the Society of Antiquaries on April 6, to assign a purpose to the large timbered buildings occupied during the first half century of the Roman conquest of Britain. It is now evident that these buildings, differing in character from both barracks and structures for domestic occupation, were port store-houses for grain and other material. The outlines of rotted beams, piles and foundation trenches, indicate that they were erected in rectangular blocks or insulce, each comprising four buildings. Of these, one faced the main road and the other three lay behind, with approaches from the side roads which bounded the insuloe. Each building was provided with a loading platform, while that facing the road had also a space in front in which carts might draw up. This building was erected on a massive beam platform, embedded in the soil, to take heavy weights; but the remaining three were erected on piles to give the ventilation necessary to protect corn against the effects of damp. No other granaries such as these are known. Another building, also unique in character, lies on the other side of the road. It is a rectangular structure erected around a court. Each side consists of two rows of rooms, ranged in pairs. It is conjectured that these were the quarters of the police guarding the stores. Dr. Bushe-Fox describes the whole base camp as an unprecedented discovery. His account of the arrangements for unloading and storing material had an almost disconcertingly modern note.

\section{Completion of the Grid in Great Britain}

THE fifth annual report of the Central Electricity Board, which has just been published, is of special interest as it is the last of the reports marking the construction of the grid in Great Britain. It has only taken six years to complete instead of the estimated eight years. The cost is less than 27 million pounds and is within $2 \frac{1}{2}$ per cent of the original estimate of the Electricity Commissioners, a very satisfactory result considering the work has been so accelerated. In future, the main business of the Central Board will be in connexion with grid trading. The main function of the grid is to see that there is an abundant supply of electrical energy at each central station so that the engineers will have more time to devote to the increase of their sales. The report shows that continuous expansion is taking place in outlying areas supplied by secondary transmission lines. The Weir Committee thought that it would be best that most of the secondary transmission should be carried out by the distributing authorities, but the Central Board found it best to regard these lines as part of the grid and so help the distributors. Successful researches have been made on methods of cheapening the cost of tapping the grid. This is a step towards supplying sparsely populated districts with electric light and power and thus encourages rural development. Instead of a tapping costing $£ 20,000$, it is hoped to reduce it to $\mathfrak{f , 0 0 0}$. It was feared at one time that difficulty would be obtained in getting wayleaves, but out of twenty-one thousand wayleaves obtained, less than six hundred $(2 \cdot 83$ per cent) had to be acquired compulsorily.

\section{The French Grid}

THE new electric transmission line which has just been opened between the Massif Central and Paris will greatly facilitate the supply of electrical energy in France. The station on the River Truyere, a tributary of the Garonne, is one of the largest and finest hydroelectric stations in Europe. We learn from the Electrician of March 24 that the pressure is 220 kilovolts ; this compares with 132 k.v., the pressure used on the British grid. The line starts from Rueynes, passes by Mareges, Eguzon and Chagny and ends at Chevilly, which is south of Paris. At present, the line can carry $100,000 \mathrm{kw}$. When the new Sarrians station is completed in a few months' time, the power transmitted will be doubled by means of a second line which is under construction. The first part of the $220 \mathrm{k} . \mathrm{v}$. line was constructed by the Paris-Orleans Railway in order to safeguard its supply for traction purposes. It was first operated at $150 \mathrm{k.v}$. , but this was modified a year ago by the addition of supplementary insulators to the strings of insulators then in use. This enables it to work at 220 k.v. Luckily, the three overhead conductors had been placed 7.8 metres apart initially, so the conversion was easily effected. The average span between the lattice towers is 250 metres and the lines are of steel-cored aluminium. The distributing stations for the Paris region are supplied by three underground lines with energy at 60,000 volts. Provision has been made so that five more of these lines can be laid when required. The important falls of the Massif Central are now connected with Paris. The joining up of the stations at the falls in the Alps and on the Rhine with the falls of the Massif Central is a most satisfactory engineering achievement.

\section{Sir Ambrose Fleming on Television}

THe fourth Exhibition of Television and PhotoElectric Apparatus was opened at the Imperial College of Science, London, S.W.7, by Sir Ambrose Fleming on April 5. In the course of his remarks, Sir Ambrose said that the invention of television has gone through the usual three stages. First, when everyone thought it could not be done at all. Second, when leading experts declared that even if it could be done, it was no possible use, and third, when the wiseacres said, we knew it could be done, but it is not a commercial proposition. "It has been my good fortune to be closely and practically connected with the introduction into great Britain of three important inventions, namely, the telephone, the incandescent electric lamp and wireless telegraphy, and I have seen these three stages illustrated in them all. Television by Baird's system is now a practical achievement and capable of being of real entertuin. ment value, as those know who have seen the nightly demonstrations of it by a good receiver. Our great grievance at present is the impossible hour at which the B.B.C. broadcast it, namely, 11-11.30 p.m." There is need for a careful scientific study of the 
subjects that can be 'televised'. Television is a new art and has new principles connected with it. The substantial facts on which it is based are well known and the keen amateur is doing not a little to push it forward. This exhibition showed how much has been done in this respect, and also how much is being done by great corporations with large resources.

Ir is, however, necessary that the ideas of the public on television should not beturned in the wrong direction by exaggerated or imaginary statements as to its real and possible achievements, because then only disappointment results when the true facts are known. "We cannot yet televise directly a cricket match at Lords or a Cup football contest at the Crystal Palace. But what we can do is to take on a moving film with a camera certain not very quickly moving objects of large size and televise this film. There is an immense field in this respect for educational work. The Latin poet Horace told us, what every advertiser knows well, namely, that memory of the eye is more tenacious than memory through the ear. We can televise geometrical diagrams, lessons in botany, physies, and zoology, and countless other useful visions. Let us hope that this new weapon science has provided will not be vulgarised or put to base uses, but employed for the instruction, elevation and national entertainment of the public at large."

\section{Eugenics and Marriage Laws}

IN a note contributed to the Bulletin of Hygiene for February, Lettin M. Crump discusses the introduction of pre-marital health certificates from the point of view of eugenics. In Mexico, impediments to marriage include insanity, and similar restrictions extending to imbecility or feeblemindedness are found in certain of the United States. The growing practice of requiring a certificate from a qualified medical practitioner for insurance purposes, as well as from candidates for public appointments, seems likely to undermine opposition on this score, and with a more enlightened public opinion the need for compulsion would be greatly lessened. In some countries, notably Austria, Germany and some of the United States, the establishment of centres for giving advice on all matters concerning marriage has found favour. Useful advice can only be given when the investigator has a knowledge of the applicant's physical and mental condition as well as of his hereditary background and that of his proposed partner, the type of inheritance of any heritable disease or defect which may be present in the pedigree and of the effect which other causes may have upon the appearance of such heritable conditions. Mendelism provides us with a growing body of available information concerning inheritance in man, and evidence collected in the working of marriage advice bureaux leads to the conclusion that feeblemindedness is in many cases inherited and usually behaves as a recessive; the mating of possible heterozygotes is undoubtedly to be discouraged. Although evidence collected from pedigrees is frequently both vague and faulty, justice demands that every available means of making public such information as exists should be fully used so as to enable the conscientious citizen to avoid handing on defects from generation to generation.

\section{Anthropological Teaching and Research in Australia}

Tue passing of a resolution by the Australian and New Zealand Association for the Advancement of Science at its meeting at Sydney in August last, urging upon the Government the need for anthropological training for all white people who hold positions of authority or control over natives, has moved Prof. Raymond Firth to open the new volume of Oceania (vol. 3, pt. 1) with a survey of the progress of anthropology in Australia in the period 1926-32. The choice of this period as the limit of his survey is determined by the fact that its beginning coincides with the setting up of a Department of Anthropology in the University of Sydney and the appointment of Prof. A. Radeliffe-Brown to the chair, as the result of a resolution passed at the Australian meeting of the Pan-Pacific Congress in 1923. At the same time, a comprehensive scheme of research was initiated under the direction of the Committee for Anthropological Research of the Australian National Research Council, for which funds have been generously provided by the Rockefeller Foundation. In what has been accomplished, much has been due to Prof. Radcliffe-Brown, who, in virtue of his position in the University of Sydney and on the Research Council, has acted as a link in bringing closely together teaching and research. Investigation has been directed to both human biology and social anthropology. Not only has the work of Spencer and Gillen in central and northern Australia been con. tinued and extended, but Prof. Radcliffe-Brown and others have also conducted investigations in areas in the east and the west of the continent. In looking forward, Prof. Firth sees that much virgin soil has to be explored, not only in Australia, but also in New Guinea and Melanesia; but in the first-named, he points out, there is need for haste lest the material vanish.

\section{Racial Distributions in Palæolithic Europe}

IN some 'notes' contributed to the Proceedings of the Prehistoric Society of East Anglia (vol. 7, pt. 1) Mr. M. C. Burkitt offers some interesting suggestions as to the possibly dual origin of the races and cultures of palæolithic age in Europe. He points out that it is no longer possible to accept the unfailing regularity of the sequence of cultures as originally classified by the French archæologists, and points to the contemporary existence, as proved by the fossil fauna, of a core industry, the coup de poing of ChelleoAcheulean times, on the west bank of the Rhine and of flake industries on the east bank, the two intermingling on the border line in eastern France, in southern Belgium and in Britain as seen in the Levallois and Clactonian industries. He goes on to point out that, while the coup de poing does not occur east of the Rhine with a few exceptions, the flake industry can be traced, except for certain gaps, from east of the Rhine right across Europe and Asia 